\title{
Less is more in physics: a small-scale Writing in the Disciplines (WiD) intervention
}

\author{
Alessandro Narduzzo \\ University of Bath, UK \\ Trevor Day \\ University of Bath, UK
}

\begin{abstract}
This article reports on a Writing in the Disciplines (WiD) intervention for first year undergraduate physics (and joint Honours) students. A short (200-250 word) assignment was designed to maximise students' learning of specific scientific writing practices, including writing with appropriate clarity and academic style for a target audience, incorporating mathematical expressions in text, creating diagrams and referring to them in text, and appropriately using citing and referencing. Peer marking was employed to offer students formative feedback before they completed the assignment. The success of the assignment as a vehicle for student learning was evaluated by reviewing the students' submissions and marks awarded, and through ten students' reported focus group responses to the experience of carrying out the assignment, their reaction to peer marking, and their responses to the assessor's written and verbal feedback. The effectiveness of the assignment's content and process, and the peer marking, are briefly discussed, and suggestions made as to how to improve this or similar assignments in future years.
\end{abstract}

Keywords: Writing in the Disciplines; physics education; peer assessment.

\section{Introduction}

I have made this [letter] longer than usual, because I have not had time to make it shorter. (Blaise Pascal (1623-62), Lettres Provinciales, 16) 
The assignment reported in this case study is based on two premises: that writing with brevity and precision is challenging, and that a short undergraduate assignment, and accompanying small scale research into teaching/learning practice, can be designed to maximise the learning for all those involved - students and staff.

In our experience, based on undergraduate student interviews and focus groups conducted at our university, at least some students on undergraduate science and engineering programmes lack confidence in academic forms of writing. For many in programmes where physics, mathematics and/or computer science are a major component, the avoidance of extended writing was an element influencing their choice of A-levels and subsequently their choice of degree. When they find in their degree programme that they will need to engage in extended writing, this is a challenge to their confidence and expertise.

At the research-intensive university where this assignment was carried out, students on physics, mathematics and computer science programmes may experience comparatively little extended writing in their first and second years, other than in writing various practical reports. In physics, for example, the writing of an extended dissertation (up to 40 pages in length) in their final year comes as a marked challenge, not only when it comes to formulating an extended argument, but in adopting appropriate technical conventions for the discipline.

This study arose from the observation of one of us (AN), a Teaching Fellow in Physics, that some students in their final year, when about to embark on their dissertation writing, had yet to fully master some of the basic conventions of the discipline. AN approached a writing consultant (TD) prior to designing a first-year writing assignment that would engage students in disciplinary writing, with assessment criteria focusing on writing issues of greatest concern, including inserting algebraic expressions in text, designing illustrations and referring to them in text, and citing and referencing.

The small-scale intervention that resulted draws upon a Writing in the Disciplines (WiD) pedagogical approach (Monroe, 2003; Deane and O'Neill, 2011) in which disciplinary academics collaborate with writing specialists to fine-tune assignments and shape the curriculum. This approach, already well embedded in undergraduate programmes among many leading Higher Education Institutions (HEls) in the United States, is gathering 
ground in the UK (see Ganobcsik-Williams, 2006, and Deane and O'Neill, 2011, for reviews). In addition, the intervention design drew upon established principles of engaging students in peer assessment, coupled with students giving formative feedback and feedforward to each other, to deepen students' learning and to help them improve on a task before its completion (Race, 2005; 2007). In a recent survey of HEls in the United States, fewer than one-third of Physics faculties reported using student peer assessment in their undergraduate degree programmes (Goubeaud, 2010); this is similar to the authors' experience of UK practice. While a few writing-related, student-assessed interventions in physics or physical sciences are reported in peer-reviewed journals (e.g. see literature cited in Cho and Cho, 2011), none appear to originate specifically from the UK experience and forms of communication other than the writing of practical reports or technical reviews, thus making the current study unusual.

In the intervention reported here, one of us (AN) sought to draw upon facets of good peer assessment practice as promoted in Orsmond (2011). Given that students were in their first few weeks at university, engaged in the transition to HE academic culture and as yet unfamiliar with university assessment practices, students were given set assessment criteria rather than the opportunity to negotiate ones.

The writing assignment was designed to engage students' intrinsic motivation (Ryan and Deci, 2000) by enabling them to choose a science topic relevant to the first year introductory physics module on Quantum Physics. The assignment was short, requiring just 200-250 words of written text, but had to meet specific technical criteria (see Appendix 1). While the assignment carried only $10 \%$ of the final marks for the module (or $5 \%$ depending on course programme options) it nevertheless focused on developing students' capabilities that were directly relevant to project reports that students would complete within weeks or months and that would carry substantial marks towards their first year final marks (up to $40 \%$ of their Laboratory Units, or $8 \%$ of their first year final mark). This short writing assignment was optional, insofar as students could choose not to do it and so lose 5 or $10 \%$ of the marks for that module. Of 130 students, $122(94 \%)$ chose to complete the assignment.

This case study reports on the methodology associated with the setting of the assignment, and its associated small-scale research, and reports on the study's findings, to inform further incorporation of writing assignments within the Physics undergraduate curriculum. 
The writing of this case study has encouraged the researcher-practitioners to engage in a more rigorous reflection on practice than might have otherwise occurred. The writing challenges experienced by undergraduate physics students at our university are likely to have resonance for students on other undergraduate science, engineering and technology programmes. Our findings should hold interest for teaching staff, learning developers and writing specialists working with STEM (science, technology, engineering and maths) undergraduate students.

\section{The assignment}

The writing task, originally inspired by the Explain it in 60 seconds brief articles in the particle physics magazine Symmetry (Fermilab/SLAC, 2012), had three main aims (identifiable from the coursework guidelines, Appendix 1):

1. To give students freedom to choose a topic of their own interest as long as it was related to Quantum Physics;

2. To offer students clear criteria to guide them through the task and against which to assess others and to be assessed;

3. To enable students to apply some conventions of scientific writing and become more proficient in their use.

The main conventions of scientific writing that were assessed were (see Appendix 1):

- Formatting, inserting and referring to an equation or symbolic expression;

- Formatting, describing and referring to a figure;

- Appropriately citing and listing 3-5 references;

- To consider the target audience (a Year 1 student in a STEM discipline) and pitch the level of explanation accordingly.

Additionally, students were encouraged to strive for clarity and effectiveness in their explanations. Appendix 1 gives the handout of assignment instructions given to students. The task was presented to the students in week 3 of the first semester, and AN started teaching his half of the Quantum Physics unit in week 6. In week 8 there was an optional coursework development session and in week 10, an optional peer feedback and marking 
session during a problems class when a peer feedback sheet (Appendix 2) was used. Friday of week 11 , the last week of teaching in semester 1 , was the deadline for electronic and paper submission.

A staff member checked each script for plagiarism using Turnitin (Turnitin, 2012), and annotated and assessed the script against the specified criteria. It was decided to return the marked coursework in a dedicated session within the Study Skills module early in the second semester, in order to provide additional verbal feedback to the whole cohort on the most common errors. For those students who did not attend this session, the scripts were passed on to their tutors. Table 1 summarises the chronology of main activities.

\begin{tabular}{|c|c|c|}
\hline \multicolumn{3}{|c|}{ Table 1. Sequence of activities for Quantum Physics writing assignment } \\
\hline \multirow[t]{5}{*}{ Semester 1} & Week 3 single session & Introduction to coursework (handout, Appendix 1) \\
\hline & Week 6 single session & AN begins teaching - reminder of assignment \\
\hline & Week 8 single session & $\begin{array}{l}\text { Assignment development session (with teaching } \\
\text { assistant) }\end{array}$ \\
\hline & $\begin{array}{l}\text { Early Week } 11 \text { single } \\
\text { session }\end{array}$ & Peer feedback plus Q \& A with AN (handout, Appendix 2) \\
\hline & End of Week 11 & Assignment submission \\
\hline \multirow[t]{2}{*}{ Semester 2} & Week 2 single session & $\begin{array}{l}\text { Marked scripts with written feedback returned to students. } \\
\text { Additional oral feedback on common problems given. }\end{array}$ \\
\hline & Week 4 & $\begin{array}{l}\text { Two student focus groups run with TD (schedule in } \\
\text { Appendix } 3 \text { ) }\end{array}$ \\
\hline
\end{tabular}

\section{Focus group methodology}

To explore the student experience of carrying out the assignment and its associated peer marking, two focus groups were run. Opportunistic sampling led to 10 students each attending one of two 45-minute focus groups. Eight of the attendees had taken part in the peer marking process; two had not. The gender balance ( 8 male, 2 female) was similar to that for the two main undergraduate programmes overall ( $75 \%$ male, $25 \%$ female).

The focus groups were carried out under British Educational Research Association (BERA) guidelines, with students not being coerced to attend, having the opportunity to opt out at any stage, and with their confidentiality and anonymity assured in any reporting. The 
groups were led by one of us (TD), with the sessions digitally audio-recorded, and the recordings and accompanying notes subsequently analysed by TD and reported to AN.

Appendix 3 gives the schedule for the guidance questions used in the focus group sessions. The focus of the questions was on three areas:

- The students' experience of carrying out the assignment;

- Their reaction to peer marking (or if they had not taken part in peer marking, why they had chosen not to);

- Their response to the written and verbal feedback on final performance given by the assessor (AN).

Students were encouraged to offer comment on anything else associated with the assignment and its marking beyond the questions in the schedule. A response to each of the schedule questions was encouraged for every member of the two focus groups.

\section{Findings}

AN analysed the students' choices and performance quantitatively, while TD analysed students' experiences qualitatively, as reported by them in the two focus groups.

Figure 1 displays the histogram for marks awarded $(n=122)$. Mode and median are both $75 \%$; the mean is $73 \%$. No mark was awarded below $45 \%$, an indication that all students had put in at least a minimum effort to achieve a pass mark (40\%). The graph is visibly skewed (skewness $=-0.58$ ) in part because the distribution is curtailed the upper end. The shape of the distribution is similar to that for the students' major first semester exam results and for second semester coursework. Means and medians are slightly higher than for other elements of the first year programme, and the assignment is unusual in that all students passed. This outcome was as intended, serving to maintain or boost students' confidence in their work at an early stage in their university studies. 
Figure 1. Histogram for the distribution of marks for the Quantum Physics assignment.

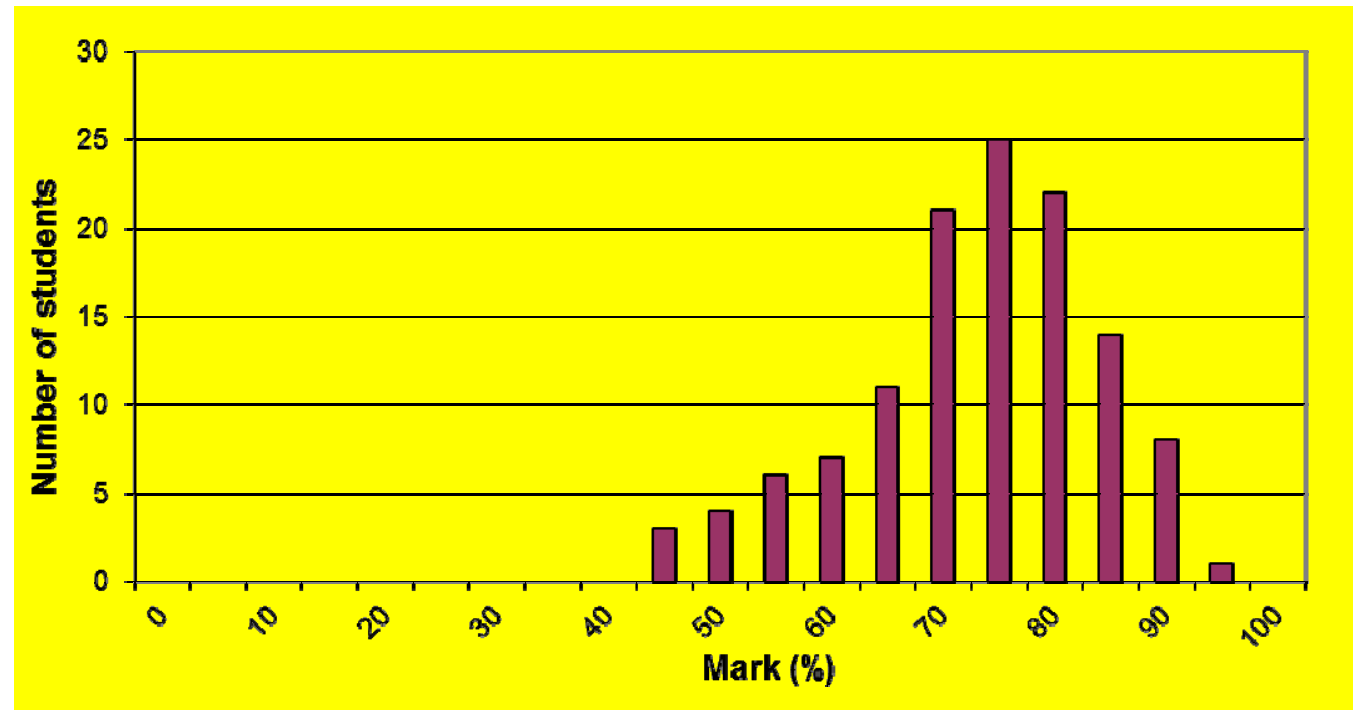

A large majority (73\%) of students chose topics that were closely linked to material presented to them during the teaching of the Unit. The most popular themes were: the Standard Model for elementary particles (16); de Broglie waves and wave-particle duality (14); the photoelectric effect (12); the Heisenberg's uncertainty principle (10); and the Bohr model (10). A significant number of these students did not make this choice out of convenience but because of genuine interest, as the content they presented was original and interesting, closely related to a syllabus topic but going beyond the lecture content. Among the other chosen topics related to the module's syllabus but less popular were Compton scattering, Millikan's experiment, the Rutherford model, and instrumentation and measurement techniques. Among the topics not immediately linked with the material presented in lectures were: Schroedinger's cat (3); the Casimir effect (2); solar sails (2); Aurora borealis (1); quantum dots (1); Cherenkov radiation (1); cosmic rays (1); and laser cooling (1). The positive outcome from the marking was that the majority of students had clearly put in an effort to achieve clarity and effectiveness, with an overall good level of success, and with a large proportion of really excellent descriptions or explanations; some students already appeared to possess their own individual and confident voice in describing physics, for example: 
A student on laser cooling:

Though initially non-intuitive, cooling atoms by laser excitation effectively reduces temperatures of atoms to the order of micro-Kelvin [Ref]. Consider an atom (velocity $\omega$ ) moving in the $+x$ direction defined in Fig. 1(a) with laser photons moving towards the atom with wavelength $\lambda$.

Another on fusion and the tunnelling effect:

The fact that proton fusion takes place in an environment with a relatively low temperature is not possible within the classical view. If two protons are going to collide, the potential energy rises rapidly and forms a potential barrier. If the potential barrier is greater than the kinetic energy of the protons, it is very unlikely that fusion will take place. Because of the uncertainty of the energy as predicted by Heisenberg, the protons can tunnel this barrier. To understand this, the wave nature of particles has to be considered.

And a student writing about the Rutherford model as a preamble to the Bohr model of the atom:

In 1911 Rutherford, with the help of Geiger and Marsden, performed an experiment using [a] gold leaf and alpha particles to explore the structure of the atom. Their results showed that the atom consisted of a dense, positively charged, central area, the nucleus, surrounded by a very light, negatively charged electron cloud [Ref]. This is Rutherford's model.

Surprisingly, the most common errors students made were in the insertion of equations within text, including inadequate punctuation and equation formatting; next most troublesome was formatting, citing and listing of references, followed by the quality of figures presented and their link to text, both in the figure caption and the main text. These shortcomings were despite the students having attended a seminar on literature searching and referencing and one on scientific writing, as well as being directed by AN to a comprehensive Guide to Citing and Referencing available on the University Library website. 
A relatively small number of students - about $20 \%$ - took part in the peer marking activity.

The feedback they gave one another identified some of the major weaknesses in drafts. Students commented on narrative clarity, structure, and appropriateness of figures and equations. Aspects that students did not consider with precision were the insertion and formatting of equations, citations and references.

\section{Students' experiences of completing the assignment}

When questioned in focus groups as to why they were set the assignment, students responded with a wide range of explanations, with only two reporting on the original impulse for the assignment, which was the concern over writing standards in the final year of the degree programme. Almost all valued the chance to choose their own topic and almost all claimed to enjoy the opportunity to pitch their article at a level appropriate to their student peers. That the assignment accrued relatively few marks was seen, by most, as beneficial, since this was the first substantial writing assignment they were to undertake on the degree programme. It was emphasised that what they learnt from this task they could then apply to more substantial writing tasks within the next few weeks or months.

Despite the assignment's product being short (200-250 words), almost all students reported finding some aspect of the assignment challenging. Several had rarely used a library and they found they lacked skills in finding appropriate books and rapidly extracting information from them (they were much more familiar with doing so from web-based material). Several found difficulty choosing a topic that they felt could be readily condensed to the assignment format. As one student put it, 'It's a compromise between what you find most interesting and what you can present the best.' For some, researching the article's content was a longer process than the writing itself. For many, it was the combination of requirements - few words, formatting the article, correct use of equations and illustrations, being pitched at the right level for the audience - that combined to create the challenge.

Many students, although introduced to a guidebook for practical report writing some weeks before the assignment was set, failed to recognise that some of the assignment's formatting requirements were illustrated in the guidebook. This lack of tight connection between one element of the course programme and another was a recurring feature 
reported by students and is addressed in the Discussion and Moving forward sections of this article.

\section{Peer marking}

The eight of ten focus group students who had engaged in peer marking reported seeing the value in critiquing and assigning marks to other people's work. It enabled them to see how their own work compared with others' and they could be influenced by the good practice and ideas they saw in others' work. Students also valued other people's comments on their own work but they felt they had been given insufficient guidance for the task. For example, they had not seen an exemplar for the assignment, and so did not appreciate the high standard required. As one student put it, 'We read [the work] quite casually, rather than looking scrupulously at what was wrong with it'. And another, 'Had we known how to mark, that session would have been really important'. They reported not appreciating, until they had completed the assignment and received feedback from the assessor, the precision with which the different criteria needed to be met. Also, they could not be confident that the marks given by themselves and others for the same piece of work were consistent.

Most students agreed that reviewing more than one example of a similar completed assignment, of varying standards and showing the marks awarded in each case for different criteria, would be helpful were the assignment to be set in future years. They suggested that students should view such examples before engaging in the peer marking exercise. Interestingly, the two female students would have liked more marks to be allocated for clarity of expression compared to the other assessment criteria, and they wanted more opportunities to develop such skills.

During the focus groups, TD explained to students that a key value in peer marking was putting oneself in the place of the formal assessor (and therefore more deeply appreciating what was needed to convince the reader that the work was of high quality). Students agreed that had that been emphasised before the peer marking, it would have helped convince them of the value of the exercise. The two students who had opted not to engage in peer marking claimed they would have found such an argument persuasive. Those two students also suggested running the peer marking in a tutorial group, rather than in the much larger and more impersonal class where the activity had taken place. 


\section{Assessor's feedback}

The assignment assessor (AN) invested considerable time in marking the students' work, by providing detailed annotations on their submitted assignment and on the mark sheet that accompanied it. The majority of students acknowledged the invaluable nature of the class session where AN gave back their work, explained the most common weaknesses (for example, failure to correctly punctuate the insertion of algebraic expressions in text), and interpreted the meaning of some of the annotations (for example, I for incorrect 'insertion' of an equation within text, $F$ for incorrect 'formatting' of an equation or a reference). The focus groups recommended that in future AN should provide coding for the different assessment criteria elements, give the coding on a mark sheet, and then use the coding in annotating the assignment. This would save time for the assessor and would give students a clear connection between marks, assessment criteria and annotated comments, which they could readily review at a later date, perhaps when they were working on their next major writing assignment.

\section{Discussion}

Taken together, the students' submitted work, observations of students discussing and asking questions about the task, and their experience of the task as reported in focus groups, all suggest that the assignment was successful in focusing students' attention in writing in a scientific manner for a specified target audience.

Peer marking, as an element of peer tutoring (Topping, 1996), has potentially many benefits for students, not least because it offers the opportunity for students to work within their zones of proximal development (ZPDs) as articulated by Lev Vygotsky (Vygotsky, 1978; Moll, 1990) with one student being guided by a more capable peer, to the benefit of both. In the current assignment, the benefits of peer marking had not been maximised, and only a fraction of students had taken part in it. Even among those students that did, they had not been convinced beforehand of the intent and value of peer marking and did not have sufficient confidence in knowing the standard of work required for the assignment, and the precise meaning of the assessment criteria.

Focus group members who had taken part in the peer marking valued other students' comments on what was wrong with their work, and benefited from seeing other students' 
work. Because the process was formative, it allowed students to make improvements before they submitted their work for formal assessment later in the same week. It also encouraged students to complete their work (or at least craft it to an advanced stage) earlier than they might otherwise have done. As indicated above, they could, nevertheless, suggest several areas for improvement in how the peer marking exercise was carried out, including using exemplars or examples of different standards.

The complexity of timetabling (constrained by having two physics undergraduate programmes and limited by availability of laboratory space) means that at least three cohorts of students complete major elements of their first year programme at different times. So, providing guidance to the entire year cohort on matters such as citing, referencing and scientific writing style is challenging, because some students have the opportunity to apply their newfound guidance within days of exposure, while others have to wait many weeks. Curriculum timetabling is being reviewed to see whether tighter linkage between skill development and application can be orchestrated.

\section{Moving forward}

Reflecting on the findings from using the assignment and peer marking with this year's cohort, for the first year of the programme next year AN intends to:

1. Have two writing assignments instead of one. Students would choose a topic as before but then write two short assignments: one aimed at a general audience 'In 150 words explain the chosen concept to a person with no scientific background'; the other a technical task with student peers as the target audience, 'Explain an equation and clarify its origin and meaning using words and images and at most 100 words'.

2. Give pedagogical justification for the writing assignments, and any associated peer marking to students at the outset, and refer to research evidence from the relevant literature.

3. Provide at least one exemplar for both kinds of assignment, but on a different topic to the ones students can choose. Given time constraints, and the commitment to modelling good practice, it is not seen as appropriate to show students a range of 
examples of different quality. However, students will be shown examples of some of the commonest errors exhibited in students' work from previous years.

4. Arrange with other staff for peer marking to take place in tutorial groups and support tutors for the task by providing them with easy access to last year's completed coursework along with the guidance that students will be receiving this year.

5. Provide a key on feedback forms explaining the coding used in marking.

6. Explain more explicitly the meaning of 'clear' and 'effective' in relation to the title and content of submitted work.

The exercise has demonstrated the value in fine-tuning the various components of an assignment so that the 'best learning value' is achieved from even a small assignment. Having a writing specialist working with a subject specialist was valuable because through knowledge transfer and combining their different perspectives, this widened and deepened their appreciation of the students' learning experience, which then informed their further work in their respective disciplines. In terms of differing perspectives, the physics specialist tended to focus more on the quality and appropriateness of figures, and the exactness of formatting of equations and symbols. The writing specialist paid more attention to the quality and appropriateness of sources, and the precision of citing and referencing. The physics specialist was more relaxed about the use of Wikipedia, whereas the writing specialist was concerned that only high quality sources should be used, and that whereas Wikipedia might be useful for an initial overview of a topic, and a pointer to reliable sources, it could not be relied upon for accuracy and should not be cited. Both were in close agreement, however, over which submissions communicated most clearly with the intended readership and which were most well rounded and engaging. Having a critical friend, in the form of the writing specialist who ran the focus groups, enabled the gathering of students' views by someone independent of the assignment creator and work assessor. The synergy between the writing and subject specialist helped develop the changes that are due to be implemented next year. The collaboration has influenced the writing development and peer assessment agenda in the department's first year programme and beyond. 


\section{Acknowledgements}

The authors would like to thank Karina Bradshaw and Justin Hodds for their help in searching the grey and peer-reviewed literature around the themes 'physics', 'physical sciences', 'peer assessment' and 'writing'.

\section{References}

Cho, Y.H. and Cho, K. (2011) 'Peer reviewers learn from giving comments', Instructional Science, 39(5), pp. 629-643.

Deane, M. and O'Neill, P. (eds.) (2011) Writing in the Disciplines. Basingstoke: Palgrave Macmillan.

Fermilab/SLAC (2012) Symmetry: dimensions of particle physics. [online] Batavia, Illinois: Fermilab/SLAC. Available at: http://www.symmetrymagazine.org/cms/ (Accessed: 20 April 2012).

Ganobcsik-Williams, L. (ed.) (2006) Teaching academic writing in UK higher education: theories, practices and models. Basingstoke: Palgrave Macmillan.

Goubeaud, K. (2010) 'How is science learning assessed at the postsecondary level? Assessment and grading practices in college biology, chemistry and physics', Journal of Science Education and Technology, 19(3), pp. 237-245.

Moll, C. (ed.) (1990) Vygotsky and education: instructional implications and applications of sociohistorical psychology. Cambridge: Cambridge University Press.

Monroe, J. (ed) (2003) Local knowledges, local practices: Writing in the Disciplines at Cornell. Pittsburgh, USA: University of Pittsburgh Press.

Orsmond, P. (2011) Self- and peer-assessment: guidance on practice in the Biosciences. $2^{\text {nd }}$ edn. Leeds: UK Centre for Bioscience, The Higher Education Academy. 
Race, P. (2005) Making learning happen: a guide for post-compulsory education. London: Sage.

Race, P. (2007) The lecturer's toolkit: a practical guide to assessment, learning and teaching. $3^{\text {rd }}$ edn. London: Routledge.

Ryan, R.M. and Deci, E.L. (2000) 'Intrinsic and extrinsic motivations: classic definitions and new directions', Contemporary Educational Psychology, 25(1), pp. 54-67.

Topping, K.J. (1996) 'The effectiveness of peer tutoring in further and higher education: a typology and review of the literature', Higher Education, 32(3), pp. 321-345.

Turnitin (2012) Plagiarism detection software. Newcastle upon Tyne: Turnitin UK. Available at: http://submit.ac.uk/en gb/home (Accessed: 30 April 2012).

Vygotsky, L.S. (1978) Mind in society. Cambridge, USA: Harvard University Press.

\section{Author details}

Dr Alessandro Narduzzo is a Teaching Fellow in the Physics Department, University of Bath, UK. His research interests include the pedagogy of physical sciences and maths in higher education. His background is as a solid state experimentalist working with unconventional metals and superconductors.

Dr Trevor Day is a Writing Consultant at the University of Bath where he runs various writing-related courses and workshops for undergraduates, postgraduates and staff. His research interests include developing undergraduates' scientific writing to meet both academic and employability imperatives. He heads the UK's National HE STEM programme 'Writing and Communicating in STEM Disciplines' special interest group. 


\section{Appendices}

\section{Appendix 1. The assignment guidelines}

\section{The task}

- Identify a science topic relevant or related to this Unit (a fundamental concept or principle, a recent discovery or claim) that interests you;

- Research it by consulting books and reading articles on it (e.g. Scientific American, Physics World, Physics Today, New Scientist);

- Present a clear and effective explanation of the chosen concept/idea in a Word or pdf document (to be uploaded onto the Unit's Moodle page) following these requirements:

- Use a title;

- Use between 200 and 250 words, including all text except references;

- Use at least one equation or symbolic expression (e.g. chemical/nuclear reaction), adequately formatted, inserted and referred to within the text;

- Use at least one figure (image or computer generated diagram or sketch) or table, with caption, adequately referred to in the text and, if necessary, referenced;

- Use between 3 and 5 references to books, articles or websites, adequately formatted and referred to in the text;

- Your explanation should be appropriate for a Year 1 University student in a STEM (Science, Technology, Engineering, Mathematics) subject.

\section{The marking scheme}

Is the content clearly communicated?

Are title and overall presentation effective?

Word count

Equation(s)/Symbolic expression(s)

Figure(s)

References

We will have one surgery/discussion session on this in week 9 , a peer feedback and assessment session in week 10 or 11 , with final Moodle submission by $5 \mathrm{pm}$ on Friday $16^{\text {th }}$ December. A severe penalty will be applied for late submission. Your coursework will be submitted to Turnitin (the antiplagiarism software). 


\section{Appendix 2. The peer feedback and marking guidelines}

\section{The task}

- Identify a science topic relevant or related to this Unit (a fundamental concept or principle, a recent discovery or claim) that interests you;

- Research it by consulting books and reading articles on it (e.g. Scientific American, Physics World, Physics Today, New Scientist);

- Present a clear and effective explanation of the chosen concept/idea in a Word or pdf document (to be uploaded onto the Unit's Moodle page) following these requirements:

- Use a title;

- Use between 200 and 250 words, including all text except references;

- Use at least one equation or symbolic expression (e.g. chemical/nuclear reaction), adequately formatted, inserted and referred to within the text;

- Use at least one figure (image or computer generated diagram or sketch) or table, with caption, adequately referred to in the text and, if necessary, referenced;

- Use between 3 and 5 references to books, articles or websites, adequately formatted and referred to in the text;

- Your explanation should be appropriate for a Year 1 University student in a STEM (Science, Technology, Engineering, Mathematics) subject.

\begin{tabular}{|l|l|r|}
\hline The feedback scheme & Comments & Mark \\
\hline $\begin{array}{l}\text { Is the content clearly } \\
\text { communicated? }\end{array}$ & $/ 3$ \\
\hline $\begin{array}{l}\text { Are title and overall } \\
\text { presentation effective? }\end{array}$ & & 12 \\
\hline Word count & & 11 \\
\hline $\begin{array}{l}\text { Equation(s)/Symbolic } \\
\text { expression(s) }\end{array}$ & & $/ 1$ \\
\hline Figure(s) & & 12 \\
\hline References & & $1 /$ \\
\hline
\end{tabular}

We will have one surgery/discussion session on this in week 9 , a peer feedback and assessment session in week 10 or 11 , with final Moodle submission by $5 \mathrm{pm}$ on Friday $16^{\text {th }}$ December. A severe penalty will be applied for late submission. Your coursework will be submitted to Turnitin (the antiplagiarism software). 


\section{Appendix 3. Focus Group: Guidance Schedule}

1. Completing the $\mathbf{2 0 0 - 2 5 0}$ word assignment:

(a) Why do you think you were set this assignment?

(b) How challenging did you consider the assignment to be?

(c) What did you like/value most about the assignment?

(d) What did you like/value least?

(e) Any other issues you'd like to raise about completing the assignment?

\section{2i. For those who did not do the peer marking:}

(a) You chose not to do the peer marking. Why was that?

(b) What did you do while others were peer marking?

(c) Anything else you wish to add?

2ii. For those who did peer marking:

(a) What was your experience of the peer marking? Was the guidance provided sufficient?

(b) What, if anything, did you find most challenging about the experience of doing peer marking?

(c) How might your experience/the value of this process been improved?

(d) Overall, how useful do you rate your experience of peer marking in terms of : i marking the work of others ii having your own work marked

(e) Anything else you wish to add?

\section{Feedback on the $\mathbf{2 0 0 - 2 5 0}$ word assignment by your tutor:}

(a) Were the marks you gained more than/less than/or similar to what you expected?

(b) Was the on-paper feedback/comments/guidance appropriate for you?

(c) Was the in-class (verbal) feedback/comments/guidance appropriate for you?

(d) In what way(s), if any, might the on-paper or in-class feedback have been made more appropriate for you?

\section{Is there anything else you wish to add?}

